\title{
Management of attention-deficit hyperactivity disorder in adults: focus on methylphenidate hydrochloride
}

This article was published in the following Dove Press journal:

Neuropsychiatric Disease and Treatment

10 August 2009

Number of times this article has been viewed

\author{
Rajasree Nair \\ Shannon B Moss \\ Baylor Family Medicine Residency \\ at Garland, Garland, Texas, USA
}

Correspondence: Rajasree Nair, MD Director of Curriculum Development, Baylor Family Medicine Residency at Garland, 60I, Clara Barton Blvd, Suite 340, Garland, Texas 75042, USA

Tel + I 972-272-5935

Fax + I 972-272-9|37

Email rajasren@baylorhealth.edu

\begin{abstract}
Attention-deficit hyperactivity disorder (ADHD) is one of the most common psychiatric disorders in young adults and causes significant psychosocial impairment and economic burden to society. Because of the paucity of long-term evidence and lack of national guidelines for diagnosis and management of adult ADHD, most of the data are based on experience derived from management of childhood ADHD. This article reviews the current evidence for the diagnosis and management of adult ADHD with special emphasis on the role of methylphenidate hydrochloride preparations in its treatment. Methylphenidate hydrochloride, a stimulant that acts through the dopaminergic and adrenergic pathways, has shown more than $75 \%$ efficacy in controlling the symptoms of adult ADHD. Although concern for diversion of the drug exists, recent data have shown benefits in preventing substance use disorders in patients with adult ADHD.
\end{abstract}

Keywords: adult ADHD, treatment, stimulants, methylphenidate hydrochloride

\section{Introduction}

Attention-deficit hyperactivity disorder (ADHD), characterized by inattention, hyperactivity and/or impulsivity, causes significant impairment in psychological, occupational and social functioning in adults. ${ }^{1-3}$ It is estimated that $1 \%$ to $36 \%$ of children diagnosed with ADHD will continue to manifest symptoms into adulthood depending on the diagnostic criteria used. ${ }^{4}$ Estimates increase to between $40 \%$ and $60 \%$ when considering persistence rates in adults experiencing partial remission. ${ }^{4}$ Recent data suggest an adult ADHD prevalence rate of $4.4 \%$ with increased incidence in males..$^{5}$ A retrospective analysis of National Ambulatory Medical Care survey over an 8-year period from 1996 to 2003 estimated a total of 10.5 million ambulatory adult ADHD visits accounting for 3.5\% of 301 million adult mental health disorder visits. ${ }^{6}$ Adult ADHD diagnosis and management pose unique challenges to physicians because of an increased incidence of comorbid psychiatric and substance use disorders in this population. These comorbidities may result in substantial undertreatment in patients with adult ADHD because of providers attributing symptoms to the comorbid psychiatric disorder rather than adult $\mathrm{ADHD} .{ }^{7}$ As a result, patients' ADHD may remain untreated, which has been shown to result in impairment in patients' self-care, mobility, cognition, and role functioning. ${ }^{3,5}$ Stimulants including methylphenidate, amphetamine and dextroamphetamine salts were the mainstay of treatment until atomoxetine, a nonstimulant, selective noradrenaline reuptake inhibitor, was approved for adult ADHD treatment. In this paper, we will briefly review the diagnosis and management 
of adult ADHD and detail the role of methylphenidate hydrochloride in the treatment of ADHD and comorbid disorders in adults.

\section{Diagnosis}

The diagnosis of adult ADHD poses challenges to clinicians as symptoms in adulthood may differ from those in childhood..$^{8-10}$ For example, the DSM criteria require behaviors such as running or climbing excessively, which are unlikely to be symptoms present in adults. ${ }^{1}$ Further, many ADHD adults learn over time to compensate for their symptoms and thus may not manifest symptoms seen in childhood. ${ }^{9,10}$ Diagnosis can be further complicated when adults present without a childhood diagnosis of ADHD and have comorbid psychiatric and substance use disorders. ${ }^{3,8}$ In a study by Faroane et al, most patients with adult ADHD were self-reported and self-referred, and there was significant delay in time to first diagnosis and initiation of treatment, especially in the primary care setting. ${ }^{3}$

\section{Diagnostic criteria}

The Diagnostic and Statistical Manual for Mental disorders, Fourth Edition Text Revision (DSM-IV-TR) requires 6 out of 9 symptoms of inattention (ie, failure to attend to detail, difficulty sustaining attention, not listening when spoken to, failure to follow through on tasks, organizational deficits, difficulty concentrating, losing items, distractibility, forgetfulness) or hyperactivity/impulsivity (ie, fidgeting, difficulty staying seated, excessive running/climbing, difficulty playing quietly, acts as though "driven by a motor", excessive talking, difficulty awaiting one's turn, interrupting frequently, prematurely responding to questions) be present for a diagnosis of ADHD. ${ }^{1}$ In addition, the symptoms must be present before age 7 and result in significant impairment observable in at least two settings. The three ADHD subtypes according to DSM criteria are: predominantly hyperactive-impulsive type, inattentive type and combined type. ${ }^{1}$ However, it is important to note that the DSM criteria were developed based on childhood presentation and may not adequately represent symptoms in adults. ${ }^{9-14}$

The Utah criteria, developed for identification of adult ADHD, may be utilized as an alternative to DSM criteria. According to these criteria, an adult must have a childhood history of ADHD and current motor hyperactivity, attention deficits and 2 of the following: labile affect, temper outbursts, excessive emotional reactivity, disorganization, impulsivity and associated features of ADHD. ${ }^{15}$ One disadvantage of these criteria is the focus on affective symptoms and requirement for hyperactivity, particularly given that these symptoms may decline more quickly over time than symptoms of inattention. ${ }^{11}$ Further, according to Utah criteria, ADHD may be diagnosed only in the absence of other psychiatric disorders, posing a diagnostic challenge given the increased incidence of comorbid psychiatric disorders. ${ }^{2,16}$

\section{Assessment}

Unfortunately, there are currently no assessments diagnostic of adult ADHD. Therefore, a multi-pronged approach including interviews, rating scales and checklists may be helpful in establishing a diagnosis. ${ }^{2,17}$ The first step is to be aware of common clinical presentations of adult ADHD. Adults with ADHD may present with cognitive (eg, difficulty concentrating, poor memory) or affective complaints (eg, anxiety, irritability, depressed mood) and/or behavioral difficulties (eg, disorganization, failure to complete projects, poor school/work performance)., ${ }^{2,3}$ Further, adults with ADHD experience higher rates of disruption in their interpersonal relationships, driving-related problems (eg, accidents, citations) and substance abuse. ${ }^{18-21}$ Employing a screening measure, such as the World Health Organization's Adult ADHD Self-Report Scale Screener, may be helpful in identifying patients for further evaluation. ${ }^{22}$

Upon suspicion of an ADHD diagnosis, it is important to first conduct a thorough interview. Patients should be queried about past and present ADHD symptoms, with information gathered from family members and previous school records if possible to establish a childhood diagnosis. ${ }^{3,23}$ Functional impairment can be assessed by querying patients about their performance in a variety of situations during the prior week, the level of effort required to function and coping strategies utilized. ${ }^{23-25}$ Assessing family history of ADHD may also be helpful given that ADHD has approximately $70 \%$ heritability. ${ }^{2,26}$ Diagnostic interviews are available to assist with the interview process, including the Brown ADD Scale, Connor's Adult ADHD Diagnostic Interview for DSM-IV and the Diagnostic Interview Schedule. ${ }^{24}$ Rating scales, many of which require no special training and take less than 5 minutes to administer (eg, Brown ADD Scale for Adults, Connor's Adult ADHD Rating Scale, Adult ADHD Self Report Scale, ADHD Rating Scale-IV), are available for administration to patients and their family members and can serve as useful adjuncts in the diagnostic process. ${ }^{22,27}$ Providers should take care to determine that symptoms are not due to other psychiatric diagnoses, such as mood disorders, anxiety disorders and personality disorders, many of which share symptoms with ADHD..$^{2,3,17,25}$ Routine laboratory and radiological tests 
are useful for differentiating ADHD from common medical conditions that can mimic symptoms of ADHD, including thyroid disorder, seizure disorders, drug interactions, hepatic diseases, lead toxicity, post-head injury, sleep disorders and hearing deficits. ${ }^{2,17}$ A complete blood count, metabolic profile and thyroid function studies can identify anemia, thyroid disorders or liver disorders. Routine radiological evaluation including computed tomography is not required for the initial diagnosis of ADHD and should be reserved for patients with a recent history of head trauma. ${ }^{2,17}$

\section{Treatment}

Similar to the diagnostic challenges mentioned above, most recommendations for the management of adult ADHD are derived from clinical experiences in childhood ADHD treatment. Currently, there is no practice guideline available in the United States for adult ADHD management. However, the British Association for Psychopharmacology (BAP) published a guideline in 2007 for ADHD management in adults and adolescents in transition to adult services. ${ }^{28}$

Adult ADHD results in significant functional and psychosocial impairment; treatment therefore consists of pharmacological, behavioral or combination interventions. As mentioned previously, comorbid psychiatric disorders and substance use disorders are not uncommon, posing unique challenges to the physician utilizing pharmacological management. ${ }^{3}$ Physicians' concerns about prescribing medications with the potential for abuse further complicate and may delay initiation of appropriate treatment. ${ }^{29}$ In addition to physician bias, insurance reimbursement sources other than private or self-pay significantly reduce the likelihood of ADHD treatment, including ADHD-specific pharmacotherapy. ${ }^{6}$

\section{Nonpharmacological treatment}

Several behavioral strategies for assisting adults with managing their ADHD symptoms have been suggested, including organizational and time management strategies. ${ }^{17,30}$ Though the research is still in its relative infancy, cognitive behavioral strategies are the most commonly investigated of the nonpharmacologic strategies. Cognitive-behavioral therapy includes identification and modification of patients' maladaptive thought patterns and behaviors and has shown statistically significant improvements in ADHD symptoms, functional impairment, depression, anxiety, hopelessness, health status and self-esteem. ${ }^{30,31}$ Skills typically taught during cognitive-behavioral therapy include education about symptoms and medications, emotional regulation, self-esteem building, problem-solving skills, mindfulness and strategies for improving motivation, concentration, listening, impulsivity, organization and time management. ${ }^{3,30,31}$ It is important to note that cognitive behavioral therapy alone may be insufficient, and thus combining it with pharmacological interventions is recommended. ${ }^{31,32}$ Family therapy and support groups may also prove a useful adjunct in adult ADHD management. ${ }^{2,17}$

\section{Pharmacologic treatment}

Stimulants and atomoxetine are the mainstay of pharmacological adult ADHD treatment and have been shown to improve symptoms of ADHD and comorbid psychiatric disorders. They have also been shown to improve associated symptoms of adult ADHD, including self-esteem, social and family functioning, driving skills and substance use risk. ${ }^{32-35}$

The most commonly used stimulants in the treatment of adult ADHD include methylphenidate hydrochloride preparations (MPH), dextroamphetamines (DEX) and mixed amphetamine salts levo amphetamine and dextroampheatmine (AMP). Pemoline, a weak stimulant medication, has been withdrawn from the market because of hepatotoxicity. ${ }^{36}$ Stimulants have shown a response rate of $25 \%$ to $78 \%$ depending on the diagnostic criteria, dose of medication administered and the presence of comorbid psychiatric disorders. Response rates of greater than $75 \%$ have been demonstrated with higher doses of both methylphenidate and mixed amphetamine salts. ${ }^{37-40}$ Lisdexamphetamine (Vyvanse $^{\circledR}$; Shire Pharmaceuticals), the once daily prodrug stimulant, was approved by the United States Food and Drug Administration (FDA) for treatment of adult ADHD in 2007. In a study of 420 adults with moderate to severe ADHD by DSM-IV criteria, lisdexamphetamine was superior to placebo in all 3 doses, and patients tolerated it well with minimal side effects. ${ }^{41}$

Despite their benefit, it is important to note that one barrier to appropriate treatment with stimulant medications is physician discomfort with prescribing controlled substances with the potential for abuse. In one study, $38 \%$ of physicians surveyed preferred prescribing a nonstimulant medication, and $58 \%$ preferred prescribing a noncontrolled medication with no evidence of abuse potential in patients with ADHD. ${ }^{29}$

Atomoxetine, a selective noradrenergic reuptake inhibitor, is the only nonstimulant medication approved by the FDA for ADHD treatment and has the benefit of not being a controlled substance. It has demonstrated efficacy in reducing 
inattentiveness, hyperactivity and impulsivity with minimal side effects in children and adolescents with ADHD. Among adults with DSM-IV criteria for ADHD, administration of atomoxetine in 2 randomized controlled trials of 10 -week duration (study $\mathrm{I}, \mathrm{n}=280$; study $\mathrm{II}, \mathrm{n}=256$ ) resulted in significant improvements in both inattentive and hyperactive/ impulsive symptoms on the Connor's Adult ADHD Rating Scales. The discontinuation rate was less than $10 \%$ in both the studies. ${ }^{42}$ The most common side effects were dry mouth, decreased appetite, insomnia, erectile dysfunction and nausea with no significant cardiovascular side effects. A recent 4-year open label study of 384 adult patients demonstrated statistically significant improvement in ADHD symptom scores with minimal side effects, demonstrating the long-term efficacy and safety of atomoxetine. ${ }^{43}$ Despite being recommended as a first-line treatment for pediatric patients with ADHD because of its comparable efficacy with stimulant medications and low abuse potential, among adult patients its use has primarily been limited to patients with comorbid substance use, psychiatric and tic disorders. ${ }^{32,44}$

Antidepressants have demonstrated less comparable efficacy than stimulants in the treatment of adult ADHD. The response is dose-related and delayed in comparison to stimulant preparations. ${ }^{45-47}$ Bupropion has been the most extensively studied of the antidepressants. In a meta-analysis of 5 clinical trials comparing the efficacy of bupropion to placebo, bupropion was 2.4 times more likely to result in improved clinical outcomes. ${ }^{47}$ The alpha-agonist clonidine has also been used in the treatment of ADHD, primarily as an adjunct to stimulants in cases of comorbid aggression, insomnia or tics. ${ }^{32,48}$

Modafinil, a novel cognitive enhancer approved for the treatment of narcolepsy, has been found to improve neuropsychological task performance in children and adults with ADHD with minimal side effects and low abuse potential. An analysis of 4 randomized control trials showed significant improvement in primary outcomes and cognitive function in ADHD patients. Insomnia and headache were the more common side effects, seen in $20 \%$ of the patients. There are no data on modafinil's long-term efficacy, and hence it may be considered in patients with ADHD who do not respond to standard treatment. ${ }^{17,49}$

Nonstimulants can also be combined with stimulants for patients with inadequate response and for treatment of comorbid psychiatric disorders. ${ }^{28,32,44}$ Patients who fail to respond to appropriate doses of stimulants may have comorbid psychiatric or developmental disorders; hence a careful re-evaluation of the patient's diagnosis is warranted. A trial of behavioral therapy may be initiated prior to adding nonstimulants in such situations. Clonidine may alleviate symptoms of impulsivity or hyperactivity and sleep disturbance or tics from use of stimulants. Bupropion may be combined with stimulants for treatment of comorbid mood disorders, bipolar or substance use disorders. ${ }^{28,32,44}$

\section{Methylphenidate in the management of adult ADHD}

Psychostimulants, especially amphetamines, were the most effective treatment for hyperactivity syndromes in children from the 1930s until methylphenidate $\left(\right.$ Ritalin $\left.^{\circledR}\right)$ received FDA approval in $1968 .{ }^{45}$ Since its introduction, methylphenidate has become the most prescribed medication for ADHD treatment in children and adults. ${ }^{33}$

\section{Mechanism of action}

Methylphenidate hydrochloride (MPH) is a piperidine derivative, structurally related to amphetamines. The exact mechanism of action of stimulants in ADHD is not completely understood, but they are presumed to act through the dopaminergic and adrenergic pathways of the frontostriatal areas in the brain..$^{50,51}$ Unlike amphetamines which can cause a direct release of dopamine and norepinephrine into the presynaptic cleft, MPH is a mild central nervous system stimulant which acts by blocking the reuptake of dopamine and norepinephrine into the presynaptic cleft by blocking the dopamine transporter protein (DAT). MPH has also been shown to reduce the availability of striatal dopamine transporter proteins in adults with ADHD. In 10 patients treated with MPH, single photon emission computed tomography (SPECT) imaging demonstrated that MPH lowered striatal DAT availability in adults with ADHD. ${ }^{52}$

MPH oral preparations are readily absorbed after oral administration with a peak plasma concentration in 2 hours. It crosses the blood-brain barrier, and $80 \%$ of the dose is excreted through urine as ritalinic acid, the main urinary metabolite. ${ }^{17}$

\section{Preparations and dosage}

MPH is available in short-, intermediate- and long-acting preparations and through a transdermal delivery system.

Short-acting preparations of $M P H$ :

i. Dexmethylphenidate or Focalin ${ }^{\circledR}$ (Novartis) $(2.5,5,10 \mathrm{mg}$ capsules)

ii. Methylin ${ }^{\circledR}(5,10,20 \mathrm{mg}$ tablets $)$

iii. $\operatorname{Ritalin}^{\circledR}(5,10,20 \mathrm{mg})$.

Intermediate-acting preparations:

i. $\quad$ Metadate $^{\circledR}$ ER $(10,20 \mathrm{mg}$ capsules $)$

ii. Methylin $^{\circledR}$ ER (10, $20 \mathrm{mg}$ capsules) 
iii. Ritalin ${ }^{\circledR}$ SR $(20 \mathrm{mg})$

iv. Metadate ${ }^{\circledR} \mathrm{CD}(10,20,30,40,50,60 \mathrm{mg})$

v. $\operatorname{Ritalin}^{\circledR} \operatorname{LA}(10,20,30,40 \mathrm{mg})$.

Long-acting preparations:

i. Concerta $^{\circledR}$ (Ortho-McNeil-Janssen) [extended-release oral osmotic release system (OROS) tablets] $(18,27,36$, $54 \mathrm{mg}$ capsules)

ii. Focalin ${ }^{\circledR} \mathrm{XR}(5,10,15,20 \mathrm{mg}$ capsules $)$

iii. Daytrana ${ }^{\circledR}$ (Shire Pharmaceuticals), the transdermal drug delivery system $(10,15,20,30 \mathrm{mg}$ patches $)$.

Dexmethylphenidate $\left(\right.$ Focalin $\left.^{\circledR}\right)$ is a more potent d-threo enantiomer of racemic methylphenidate approved for ADHD treatment with a high affinity for dopamine transporter (DAT) and requires only half the total dose of immediate acting MPH preparations. Focalin ${ }^{\circledR} \mathrm{XR}$ is the extended-release formulation with a bimodal release pattern with bead delivery system. Each capsule of Focalin ${ }^{\circledR}$ XR contains half the dose as immediate-release MPH beads and the other half as enteric coated delayed-release beads. OROS methylphenidate $\left(\right.$ Concerta $^{\circledR}$ ) was approved by FDA in 2008 for use in adults and uses an oral osmotic release system for its longer duration of action. Each capsule contains 2 drug compartments and a water absorption compartment. $22 \%$ of the drug is coated on the outside of the capsule and results in immediate relief of symptoms; the remaining $78 \%$ of the medication is released more slowly. ${ }^{17}$ Due to this unique drug delivery system it cannot be crushed, injected or inhaled, further reducing the abuse potential. Daytrana is the transdermal delivery system of MPH and is well tolerated. Methylin ${ }^{\circledR}$ and Ritalin ${ }^{\circledR}$ SR are available in generic format; Metadate ${ }^{\circledR} \mathrm{CD}$ and Ritalin ${ }^{\circledR} \mathrm{LA}$ capsules can be opened and sprinkled on soft food. All MPH preparations are schedule II controlled substances due to the potential for abuse. ${ }^{32}$

The initial starting dose is $10 \mathrm{mg}$ /day for short-acting preparations, and the dose is titrated by 5 to $10 \mathrm{mg}$ weekly to a maximum dose based on response and side effects (Table 1). The first dose is typically given in the morning with the additional dose in the afternoon or early evening for optimal symptom control. Late evening doses may exacerbate symptoms of insomnia and hence should be avoided. Long-acting preparations maybe ideal for adolescents and adults due to increased compliance and lesser abuse potential. Short-acting preparations can be combined with long-acting preparation for optimal symptom control during the day time. ${ }^{17}$

\section{Efficacy of methylphenidate in adult ADHD}

MPH has been shown to reduce symptoms of hyperactivity, impulsivity and inattentiveness and to improve on-task behavior, academic performance and social functioning in children and adolescents. ${ }^{32,53}$ Although earlier studies on the efficacy of MPH in the management of adult ADHD showed equivocal results due to low doses of medication, the presence of comorbid disorders and the varying diagnostic criteria used, recent results have been promising (Table 2). ${ }^{40,54}$ In 1995, Spencer and colleagues conducted a randomized, 7-week, placebo-controlled, crossover study of MPH in 23 adult patients meeting DSM-III-R ADHD criteria. A daily dose of $1.0 \mathrm{mg} / \mathrm{kg}$ per day of MPH resulted in a marked therapeutic response as compared to placebo (78\% vs $4 \%$, $P<0.0001)$ in 18 of the 23 subjects, independent of gender, comorbid anxiety or depression or family history of psychiatric disorders. ${ }^{40}$ Similar results (76\% MPH vs $19 \%$ placebo) were reported by these authors in a later study of 146 adult patients with ADHD with a daily dosing of $1.1 \mathrm{mg} / \mathrm{kg} /$ day of MPH. ${ }^{38}$ A 2004 meta-analysis of 6 studies (140 MPH treated adults and 113 placebo treated adults) showed a mean effect size of $0.9(\mathrm{z}=4.3, P<0.001)$, which was similar to the effects observed with earlier studies in children and adolescents. Larger effect sizes $(1.3, P<0.02)$ were associated with physician ratings of outcomes and larger doses of MPH (0.9 mg/kg/day or higher). ${ }^{53}$

Long-acting preparations have a similar efficacy rate with greater convenience and compliance due to single daily dosing. ${ }^{32,55-59}$ In one study, once daily dosing of equipotent extended-release OROS MPH tablets $\left(\right.$ Concerta $^{\circledR}$ ) had similar efficacy to 3 times per day dosing of immediaterelease $\mathrm{MPH} .{ }^{59}$ In a double-blind trial of 401 adults with ADHD, those treated with OROS methylphenidate $(18 \mathrm{mg}$, $36 \mathrm{mg}$, or $72 \mathrm{mg} /$ day), demonstrated significant improvement in total symptom score as measured by Connor's Adult ADHD Rating Scale (mean change $=-10.6$ for $18 \mathrm{mg}$, $P=0.01 ;-11.5$ for $36 \mathrm{mg}, P=0.01 ;-13.7$ for $72 \mathrm{mg}$, $P<0.001 ;-7.6$ for placebo). ${ }^{55}$ Improvement in executive function and oppositional/defiant symptoms has also been demonstrated in adults treated with OROS MPH. ${ }^{57,59}$ Most of the earlier studies were of short duration, thus data on the long-term efficacy and safety of these drugs are limited. However, a recent study of extended-release methylphenidate (methylphenidate ER) in 359 subjects for 24 weeks showed clinically and statistically significant sustained improvements in ADHD symptoms. ${ }^{61}$

Some differences in efficacy have been suggested depending on time of ADHD onset and ADHD subtype. However, in a recent study, when MPH was administered to children and adults meeting DSM-IV ADHD criteria, those meeting the childhood onset criterion had no better response 


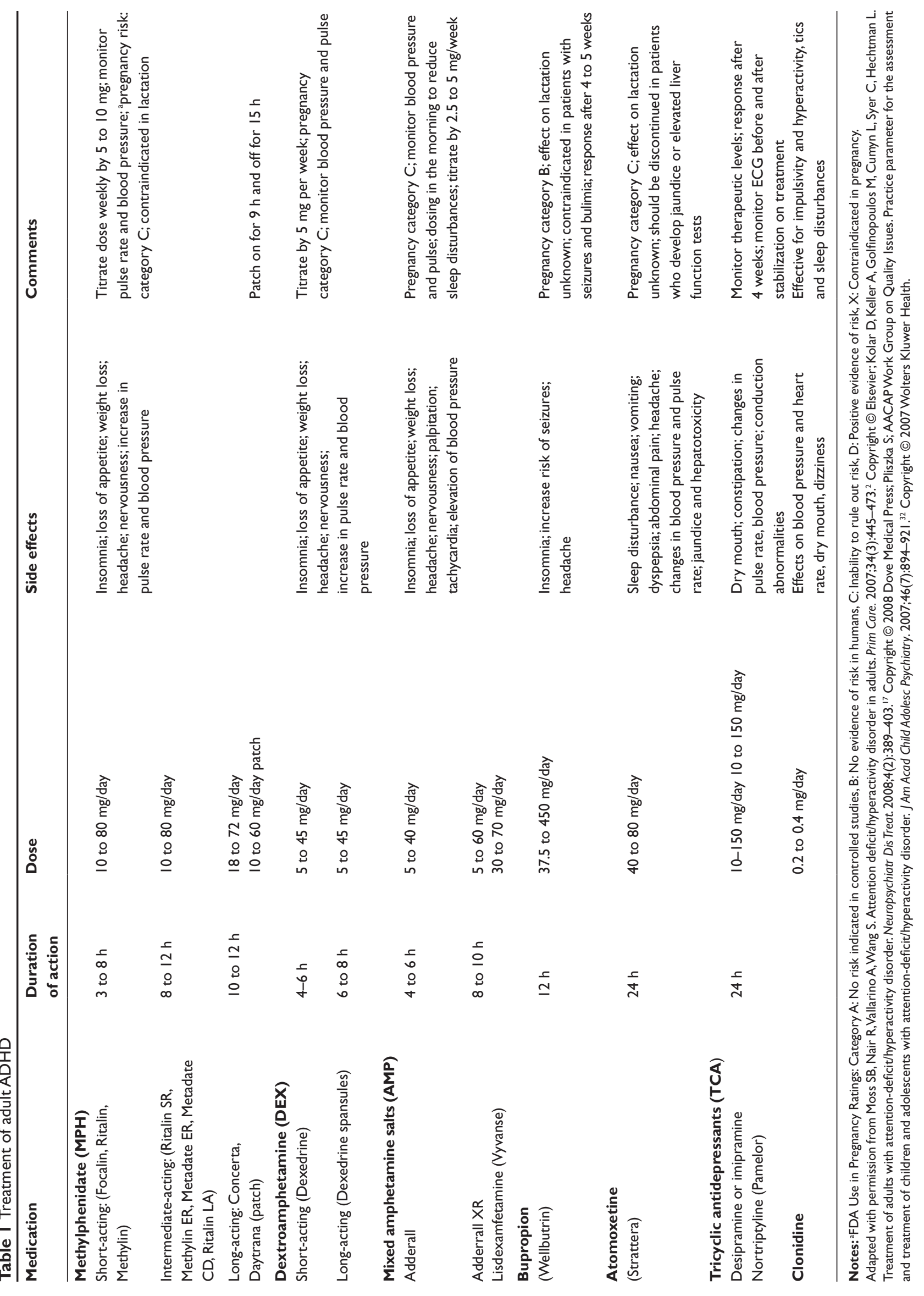


to methylphenidate at doses of $0.5 \mathrm{mg} / \mathrm{kg} /$ day than subjects with late-onset ADHD (eg, not meeting the childhood onset criterion). ${ }^{62}$ A comparative analysis of the efficacy of MPH on the subtypes of ADHD in children (ADHD inattentive type vs ADHD combined type) indicated that MPH's predominant effect was on hyperactivity and aggression in children with ADHD combined type. Effect on inattention and task performance was equal among the two groups in children. ${ }^{63}$

As previously mentioned, adult ADHD patients have high rates of comorbid substance use disorders and, as a result, physicians are sometimes hesitant to initiate stimulant treatment in this population. However, research indicates that this hesitation may not be well-founded. In a meta-analysis of 6 studies of children, adolescents and adults treated with stimulants for a minimum of 4 years ( 2 with follow-up in adolescence and 4 in young adulthood) and with information on childhood treatment with stimulants, a substantial reduction in subsequent alcohol and other substance use disorders was found. ${ }^{35}$ Similarly, a recent 10 -year prospective follow-up study of 140 children with ADHD treated with stimulants found no significant increase or decrease in alcohol, drug or nicotine use disorders. ${ }^{64}$ In patients diagnosed with comorbid substance use disorders, the results are also promising. In one study, long-acting MPH was shown

Table 2 Efficacy of methylphenidate (MPH) in the treatment of ADHD $38,53,55-58,60,61$

\begin{tabular}{|c|c|c|c|c|}
\hline Study & $\mathbf{N}$ & Method & Duration & Conclusion \\
\hline Faraone $^{53}$ & 253 & $\begin{array}{l}\text { Meta-analysis of } 6 \text { randomized } \\
\text { placebo controlled trials }\end{array}$ & & $\begin{array}{l}\text { Mean effect size for MPH was } 0.9 \\
(P<0.00 \mathrm{I}) \text { and larger effect size of I.3 } \\
\text { was noticed with higher doses of MPH } \\
(>0.9 \mathrm{mg} / \mathrm{kg} / \text { day })\end{array}$ \\
\hline Spencer ${ }^{38}$ & 146 & $\begin{array}{l}\text { Randomized, placebo-controlled, } \\
\text { parallel study }\end{array}$ & 6 weeks & Therapeutic response (76\% vs 19\%) \\
\hline Medori ${ }^{55}$ & 401 & $\begin{array}{l}\text { Randomized, double blind, } \\
\text { placebo controlled study of } \\
18,36 \text { and } 72 \mathrm{mg} \text { of OROS MPH }\end{array}$ & 5 weeks & $\begin{array}{l}\text { Change in total score on Connor's Adult } \\
\text { ADHD Rating Scale: mean change }-10.6 \\
(P=0.0 \mathrm{I}) \text { for } 18 \mathrm{mg},-\mathrm{II} .5(P=0.0 \mathrm{I}) \\
\text { for } 36 \mathrm{mg} \text {, and }-\mathrm{I} 3.7(P<0.00 \mathrm{I}) \text { for } \\
72 \mathrm{mg} \text { vs }-7.6 \text { for placebo }\end{array}$ \\
\hline Rosler ${ }^{61}$ & 359 & $\begin{array}{l}\text { Randomized, placebo controlled, } \\
\text { parallel study of methylpheni- } \\
\text { date ER }\end{array}$ & 24 weeks & $\begin{array}{l}\text { Response of more than } 30 \% \text { reduction } \\
\text { of the WRAADDS score, } 61 \% \text { compared } \\
\text { to } 42 \% \text { in the placebo group. } 55 \% \\
\text { of subjects on MPH and } 37 \% \text { placebo } \\
\text { showed improvement in CGIS }\end{array}$ \\
\hline Biederman $^{58}$ & $|4|$ & $\begin{array}{l}\text { Randomized placebo controlled, } \\
\text { parallel study of OROS MPH }\end{array}$ & 6 week & $\begin{array}{l}66 \% \text { of subjects }(n=44) \text { on OROS } \\
\text { MPH and } 39 \% \text { of subjects }(n=23) \\
\text { on placebo showed improvement in } \\
\text { CGIS and }>30 \% \text { reduction in Adult } \\
\text { ADHD Investigator System Report } \\
\text { Scale Score }\end{array}$ \\
\hline Jain $U^{56}$ & 50 & $\begin{array}{l}\text { Double blind, placebo controlled, } \\
\text { cross over study using once daily } \\
\text { novel biphasic multilayer release } \\
\text { (MLR) methylphenidate }\end{array}$ & 6 weeks & $\begin{array}{l}\text { Improvement in CGIS (Global } \\
\text { Improvement: } 2.6 \text { vs } 3.7 ; P=0.0015) \text {, } \\
\text { CAARS-S (I } 2.2 \text { vs } 5.4 ; P=0.0083) \text {, and } \\
\text { CAARS-O (I0.9 vs } 6.6 ; P=0.1404)\end{array}$ \\
\hline Reimherr ${ }^{57}$ & 47 & $\begin{array}{l}\text { Double blind, placebo controlled, } \\
\text { crossover trial of OROS MPH }\end{array}$ & & $\begin{array}{l}40 \%(\mathrm{~N}=19) \text { had ADHD with both } \\
\text { significant emotional and oppositional } \\
\text { symptoms. OROS methylphenidate } \\
\text { superior to placebo for all clinical } \\
\text { measures: total WRAADDS score } \\
\text { decrease of } 42 \% \text { vs I3\%, } P<0.00 \text { I and } \\
\text { total ADHD-RS score decrease of } 41 \% \\
\text { vs } 14 \%, P=0.003\end{array}$ \\
\hline Fallu ${ }^{60}$ & 30 & Pilot, uncontrolled, open label & 38 days & $\begin{array}{l}\text { Statistically significant improvements } \\
\text { observed in executive function }\end{array}$ \\
\hline
\end{tabular}

Abbreviations: ADHD-RS, Adult ADHD-Rating Scale; CAARS-S, Conners' Adult ADHD Rating Scales Self-rated; CAARS-O, Conners' Adult ADHD Rating Scales Observer Rated; CGI-I, Clinical Global Impressions-Improvement scale; WRAADDS, Wender-Reimherr Adult Attention Deficit Disorder Scale. 
to be effective in controlling the symptoms of ADHD in patients with cocaine dependence in complete remission without any relapse of abuse. ${ }^{33}$ Interestingly, a 14-week trial comparing the efficacy of sustained-release MPH to placebo in the treatment of cocaine-dependent adults with ADHD failed to demonstrate a significant reduction in ADHD symptoms, but did result in a reduction in cocaine use among MPH-treated patients. ${ }^{65}$ However, MPH is still considered a second line agent for treatment of patients with adult ADHD and comorbid substance abuse disorder who do not respond to antidepressants or atomoxetine. Long-acting preparations with less abuse potential and close monitoring of patients is required if initiated on MPH. . $^{217,33}$

\section{Comparison of methylphenidate with other pharmacological agents for ADHD}

Data comparing the different pharmacological agents available for the treatment of adult ADHD are very limited. Most of the clinical evidence is derived from studies on children and adolescents. When studies among adults do exist, the majority are placebo-controlled trials and not direct comparisons of the different drugs. In a meta-analysis seeking to provide an indirect comparison of short-acting immediate-release MPH with longeracting stimulants, bupropion and atomoxetine, 22 placebo controlled trials $(n=2203)$ were evaluated. The relative risk of clinical response was 4.32 for short-acting stimulants (95\% CI 3.03, 6.16), 1.87 for long-acting bupropion $(95 \%$ CI $1.36,2.58)$ and 1.35 for longer-acting stimulants (95\% CI 0.997, 1.84). The authors concluded immediaterelease MPH was more effective for the treatment of ADHD and comorbid substance use disorders with no significant adverse effects. ${ }^{6}$

\section{Amphetamines}

There are minimal data comparing the efficacy of amphetamines with MPH preparations in adults and children, but available data suggest no significant difference in efficacy, side effect profiles or response rates between MPH preparation and amphetamine salts. ${ }^{38,40,54}$ In a study comparing the efficacy of OROS MPH (72 mg), extended-release amphetamine salts $(30 \mathrm{mg})$ and placebo in improving simulated driving performance among 35 adolescent drivers with ADHD, OROS MPH resulted in a significant improvement in driving performance among adolescents with ADHD. Mixed amphetamine salts did not exhibit statistical significance over placebo in the driving performance of adolescents. $^{35}$

\section{Atomoxetine}

There are no data directly comparing atomoxetine and MPH in the treatment of adult ADHD. Earlier studies in children and adults demonstrated response rates similar to MPH in ADHD symptom reduction with minimal side effects. ${ }^{31,42}$ Despite comparable efficacy, there is some indication of bias in atomoxetine prescription practices. A 2006 utilization study compared prescribing practices of atomoxetine versus long-acting stimulants for adult ADHD three years after the introduction of atomoxetine for the treatment of adult ADHD. Results indicated that younger patients and females were less likely to receive atomoxetine, and patients with past-year claims for alcohol and drug dependence, psychosis, bipolar disorder and anxiety disorders were more likely to receive atomoxetine. $^{44}$

\section{Bupropion}

Sustained-release bupropion has been used off-label in the treatment of adult ADHD, particularly when patients present with comorbid depression or substance abuse disorders. However, there are very limited data comparing the efficacy of bupropion to MPH in adult ADHD treatment. In a 7-week randomized controlled trial, adult ADHD symptom reduction as measured by the Clinical Global Impression scale was $50 \%$ for methylphenidate, $64 \%$ for sustained-release bupropion and $27 \%$ for placebo. ${ }^{67}$ A 12-week trial comparing the efficacy of sustained-release $\mathrm{MPH}$ or sustained-release bupropion to placebo in treating ADHD symptoms in methadone-maintained subjects with cocaine dependence or abuse did not show any significant difference between treatments because of a high placebo response. Further, there was no misuse of medication or worsening of cocaine use in subjects treated with MPH. ${ }^{68}$

\section{Clonidine}

Clonidine is commonly used in the treatment of ADHD, particularly when patients present with comorbid aggression, insomnia or tic disorder. However, data on its use in adult ADHD are lacking. In a clinical trial of 122 children aged 7 to 12 , subjects were randomly assigned to clonidine, $\mathrm{MPH}$, combined clonidine/MPH or placebo. Results indicated no significant benefit of clonidine over MPH as measured by the Connor's Teachers Abbreviated Symptom Questionnaire. ${ }^{69}$

\section{Side effects}

Similar to other stimulants, MPH can cause mild disturbances in mood, appetite and sleep which can be minimized by using the lowest effective dose and using 
long-acting preparations..$^{2,17,32,33}$ The most common side effects of long-acting preparations include headache, decreased appetite, insomnia, nervousness and nausea. ${ }^{32,55,56}$ Patients appear to be fairly tolerant of side effects, one study showing only $4.3 \%$ of patients treated with OROS MPH discontinuing treatment due to an adverse event. ${ }^{55}$ MPH preparations should be used with caution in patients with prior history of seizure disorders as it can initiate seizures in higher doses. ${ }^{33} \mathrm{MPH}$ and other stimulants are contraindicated in patients with glaucoma, hyperthyroidism, hypertension, acute psychosis and those using monoamine oxidase inhibitors. ${ }^{33}$

Diversion of stimulants has been a significant concern among physicians in initiating treatment for adult ADHD. These medications, particularly the short-acting preparations, are abused orally, through nasal insufflations after grinding or by injecting the dissolved drug. Approximately $7 \%$ to $11 \%$ of adolescents and young adults have reported diverting their stimulant medications. Further, approximately $11 \%$ of students without ADHD reported using MPH or amphetamine for recreational purposes. ${ }^{70}$

Drug holidays, or the discontinuation of treatment during weekends and holidays in an effort to minimize adverse effects, should be discouraged due to lack of evidence supporting their benefit. , $8,17,32,33^{2}$

\section{Monitoring parameters}

Because of the effects of MPH and other stimulants on weight, blood pressure and heart rate, patients' vital signs should be closely monitored prior to therapy initiation and at periodic intervals thereafter (AHA recommendation Class I recommendation, level of evidence C). ${ }^{32,37,58,71-73}$ Although adult data are not available, the estimated rate of sudden death in children treated with MPH between January 1992 and December 2004 was calculated to be 0.2/100,000 patient-years, well below the rate of sudden death in the general pediatric population. ${ }^{32}$ Despite this, it is important to exercise caution when initiating treatment. In April 2008, the American Heart Association recommended evaluation for cardiac disease in children prior to initiating therapy with MPH and other stimulants and atomoxetine due to FDA warnings of cardiac deaths in children. Most of these mortalities occurred in patients with underlying structural heart disease (eg, hypertrophic cardiomyopathy). Cases of sudden cardiac death have been reported when prescribing MPH in combination with clonidine; however, such events are rare when MPH is used as a single agent. Patients should be queried about a personal history of heart disease, symptoms of palpitation, dizziness or syncope and a family history of sudden cardiac death prior to age 40, long QT syndrome, arrhythmias and hypertrophic cardiomyopathy. A detailed medication and substance abuse history should be elicited prior to the initiation of treatment. A baseline electrocardiogram, though not mandatory, is also recommended prior to initiation of stimulant treatment (Class IIa recommendation, level of evidence C). ${ }^{73}$

Due to the increased incidence of psychotic and manic symptoms among patients receiving stimulant treatment, the FDA warns that patients should also be monitored closely for psychosis and suicidal ideation while on stimulant medications. ${ }^{74}$ It should be noted that patients treated with atomoxetine should also be closely monitored for these symptoms, as they are more commonly reported with atomoxetine than MPH. Patients should also be closely monitored for compliance with their medication regimen and for medication and other substance abuse, including random drug screens. ${ }^{2,32}$

\section{Effect of methylphenidate on pregnancy and lactation}

To date, there are limited human studies examining prenatal and breastfeeding risk. Earlier drug monitoring studies did not observe increased incidence of birth defects due to MPH exposure. ${ }^{75}$ The National Toxicology Program Center for the Evaluation of Risks to Human Reproduction reported in 2005 that there are insufficient data for pregnancy loss and reproductive effects with MPH use in pregnancy. ${ }^{76}$ However, because of limited human data and animal data suggesting moderate risk during pregnancy, all stimulants (including $\mathrm{MPH}$ ) carry category $\mathrm{C}$ risk in pregnancy. ${ }^{75,76}$ Despite potential for risk, there is no recommendation for termination of pregnancy for maternal exposure to MPH. However, patients should be closely monitored and counseled about the possibility of emergence of symptoms or unfavorable physiological side effects (such as changes in heart rate, blood pressure) owing to sudden withdrawal of stimulant drugs during pregnancy. ${ }^{79}$

Data on MPH safety during lactation is limited, but it is presumed to be passed to the nursing infant due to its low molecular weight. The American Academy of Pediatrics recommends against breastfeeding while on MPH and other stimulant medications. ${ }^{75}$

\section{Cost}

Earlier cost and efficacy studies of drug treatments for ADHD in children and youth indicated no significant 
differences among treatments; however, immediate-release $\mathrm{MPH}$ and extended-release MPH preparations had lower total expected costs. ${ }^{78,79}$ In a 6-month follow up of 4569 patients receiving 3 alternative drug therapies for ADHD (OROS MPH, extended-release mixed amphetamine salts, atomoxetine), adults treated with OROS MPH had slightly lower medical and total medical and drug costs than those treated with MAS-XR or atomoxetine after adjusting for patient characteristics including substance abuse, depression, and comorbid disorders. The comparison of risk-adjusted total direct costs, including drug cost, was on average US\$156 less $(8.0 \%$, US\$1,782 vs US\$1,938) for OROSMPH compared with extended-release mixed amphetamine salts $(P=0.017)$ and $\$ 226$ less $(11.3 \%, \$ 1,782$ vs. $\$ 2,008)$ compared with atomoxetine $(P<0.001){ }^{80}$

\section{Conclusions}

Adult ADHD causes academic, occupational and social dysfunction with significant economic burden to society. Currently, there are no national guidelines to aid physicians in the diagnosis and management of adult ADHD, and most of the treatment principles are based on evidence from childhood ADHD treatment. In spite of the advent of longer-acting and nonstimulant medications for the treatment of ADHD, MPH remains the most cost-effective treatment with clinically significant outcomes. Amid concerns for diversion of drugs for potential abuse, MPH (particularly short-acting, immediate-release $\mathrm{MPH}$ ) has been shown to decrease substance use disorders in children and young adults. Long-acting preparations are beneficial because of their potential for increased compliance and lower potential for abuse. Compared with the childhood ADHD literature, there is a significant paucity of evidence on the cardiovascular and psychiatric adverse effects in adults. Further, there is limited evidence of the comparative efficacy, including long-term efficacy, and safety of different pharmacological agents. Until more data are available, immediate-release and long-acting MPH and other stimulant medications remain the mainstay of treatment for adult ADHD.

\section{Disclosures}

The authors declare no conflicts of interest.

\section{References}

1. American Psychiatric Association. Diagnostic and Statistical Manual of Mental Disorders, 4th edition. Washington, DC: American Psychiatric Association; 2000.

2. Moss SB, Nair R, Vallarino A, Wang S. Attention deficit/hyperactivity disorder in adults. Prim Care. 2007;34(3):445-473.
3. Faraone SV, Spencer TJ, Montano CB, Biederman J. Attention-deficit/ hyperactivity disorder in adults: a survey of current practice in psychiatry and primary care. Arch Intern Med. 2004;164(11):1221-1226.

4. Faraone SV, Biederman J, Mick E. The age-dependent decline of attention deficit hyperactivity disorder: a meta-analysis of follow-up studies. Psychol Med. 2006;36:159-165.

5. Kessler RC, Adler L, Barkley R, et al. The prevalence and correlates of adult ADHD in the United States: results from the National Comorbidity Survey replication. Am J Psychiatry. 2006;163:716-723.

6. Sankaranarayanan J, Puumala SE, Kratochvil CJ. Diagnosis and treatment of adult attention-deficit/hyperactivity disorder at US ambulatory care visits from 1996 to 2003. Curr Med Res Opin. 2006;22(8): 1475-1491.

7. Barkley RA, Brown TE. Unrecognized attention-deficit/hyperactivity disorder in adults presenting with other psychiatric disorders. CNS Spectr. 2008;13:977-984.

8. Searight HR, Burke JM, Rottnek F. Adult ADHD: evaluation and treatment in family medicine. Am Fam Physician. 2000;62:2077-2086.

9. McGough JJ, Barkley RA. Diagnostic controversies in adult attention deficit hyperactivity disorder. Am J Psychiatry. 2004;161: 1948-1956.

10. Riccio CA, Wolfe M, Davis B, Romine C, George C, Lee D. Attention deficit hyperactivity disorder: manifestation in adulthood. Arch Clin Neuropsychol. 2005;20:249-269.

11. Mick E, Faraone SV, Biederman J. Age-dependent expression of attention-deficit/hyperactivity disorder symptoms. Psychiatr Clin N Am. 2004;27:215-224.

12. Mannuzza S, Klein RG, Klein DF, Bessler A, Shrout P. Accuracy of adult recall of childhood attention deficit hyperactivity disorder. Am J Psychiatr. 2002;159:1882-1888.

13. Roy-Byrne P, Scheele L, Brinkley J, et al. Adult attention-deficit hyperactivity disorder: assessment guidelines based on clinical presentation to a specialty clinic. Compr Psychiatry. 1997;38(3):133-140.

14. Applegate B, Lahey BB, Hart EL, et al. Validity of the age-of-onset criterion for ADHD: a report from the DSM-IV field trials. $J$ Am Acad Child Adolesc Psychiatry. 1997;36(9):1211-1221.

15. Ward MF, Wender PH, Reimherr FW. The Wender Utah Rating Scale: an aid in the retrospective diagnosis of childhood attention deficit hyperactivity disorder. Am J Psychiatry. 1993;150:885-890.

16. Wilens TE, Kwon A, Tanguay S, et al. Characteristics of adults with attention deficit hyperactivity disorder plus substance use disorder: the role of psychiatric comorbidity. Am J Addict. 2005;14: 319-327.

17. Kolar D, Keller A, Golfinopoulos M, Cumyn L, Syer C, Hechtman L. Treatment of adults with attention-deficit/hyperactivity disorder. Neuropsychiatr Dis Treat. 2008;4(2):389-403.

18. Biederman J, Faraone SV, Spencer TJ, Mick E, Monuteaux MC, Aleardi M. Functional impairments in adults with self-reports of diagnosed ADHD: a controlled study of 1001 adults in the community. J Clin Psychiatry. 2006;67:524-540.

19. Barkley RA, Guevremont DC, Anastopoulos AD, DuPaul GJ, Shelton TL. Driving-related risks and outcomes of attention deficit hyperactivity disorder in adolescents and young adults: a 3- to 5-year follow-up survey. Pediatrics. 1993;92(2):212-218.

20. Wilens TE, Biederman J, Mick E, Faraone SV, Spencer T. Attention deficit hyperactivity disorder (ADHD) is associated with early onset substance use disorders. J Nerv Ment Dis. 1997;185(8):475-482.

21. Biederman J, Wilens T, Mick E, Milberger S, Spencer TJ, Faraone SV. Psychoactive substance use disorders in adults with attention deficit hyperactivity disorder (ADHD): effects of ADHD and psychiatric comorbidity. Am J Psychiatry. 1995;152(11):1652-1658.

22. Kessler RC, Adler L, Ames M, et al. The World Health Organization adult ADHD self-rep ort scale (ASRS): a short screening scale for use in the general population. Psychol Med. 2005;35:245-256.

23. Gallagher R, Blader J. The diagnosis and neuropsychological assessment of adult attention deficit/hyperactivity disorder: scientific and practical guidelines. Ann NY Acad Sci. 2001;931:148-171. 
24. Asherson P. Clinical assessment and treatment of attention deficit hyperactivity disorder in adults. Expert Rev Neurotherapeutics. 2005; 5(4):525-539.

25. Wasserstein J. Diagnostic issues for adolescents and adults with ADHD. J Clin Psychol. 2005;61:535-547.

26. Faraone SV, Perlis RH, Doyle AE, et al. Molecular genetics of attention-deficit/hyperactivity disorder. Biol Psychiatry. 2005;57(11): 1313-1323.

27. Adler L, Spencer T, Faraone SV, et al. Validity of pilot Adult ADHD Self-Report Scale (ASRS) to rate adult ADHD symptoms. Ann Clin Psychiatry. 2006;18(3):145-148.

28. Nutt DJ, Fone K, Asherson P, et al. Evidence-based guidelines for management of attention-deficit/hyperactivity disorder in adolescents in transition to adult services and in adults: recommendations from the British Association for Psychopharmacology. J Psychopharmacol. 2007;21(1):10-41.

29. Stockl KM, Hughes TE, Jarrar MA, Secnik K, Perwien AR. Physician perceptions of the use of medications for attention deficit hyperactivity disorder. J Manag Care Pharm. 2003;9(5):416-423.

30. Safren SA. Cognitive-behavioral approaches to ADHD treatment in adulthood. J Clin Psychiatry. 2006;67 Supp1 8:46-50.

31. Rostain AL, Ramsay JR. A combined treatment approach for adults with ADHD - results of an open study of 43 patients. J Att Dis. 2006; 10(2):150-159.

32. Pliszka S; AACAP Work Group on Quality Issues. Practice parameter for the assessment and treatment of children and adolescents with attention-deficit/hyperactivity disorder. J Am Acad Child Adolesc Psychiatry. 2007;46(7):894-921.

33. Greenhill LL, Pliszka S, Dulcan MK, et al. American Academy of Child and Adolescent Psychiatry. Practice parameter for the use of stimulant medications in the treatment of children, adolescents, and adults. J Am Acad Child Adolesc Psychiatry. 2001;41(2 Suppl): $26 \mathrm{~S}-49 \mathrm{~S}$.

34. Wilens TE, Faraone SV, Biederman J, Gunawardene S. Does stimulant therapy of attention-deficit/hyperactivity disorder beget later substance abuse? A meta-analytic review of the literature. Pediatrics. 2003;111(1):179-185.

35. Cox DJ, Merkel RL, Moore M, Thorndike F, Muller C, Kovatchev B. Relative benefits of stimulant therapy with OROS methylphenidate versus mixed amphetamine salts extended release in improving the driving performance of adolescent drivers with attention-deficit/ hyperactivity disorder. Pediatrics. 2006;118(3):e704-e710.

36. Food and Drug Administration: Alert for healthcare professionals: Pemoline tablets and chewable tablets (marketed as Cylert). Food and Drug Administration Web site. Available from: www.fda.gov/cder/ drug/InfoSheets/HCP/pemolineHCP.htm. Accessed June 16, 2009.

37. Spencer T, Biederman J, Wilens T, et al. Efficacy of a mixed amphetamine salts compound in adults with attention-deficit/hyperactivity disorder. Arch Gen Psychiatry. 2001;58(8):775-782.

38. Spencer T, Biederman J, Wilens T, et al. A large, double-blind, randomized clinical trial of methylphenidate in the treatment of adults with attention-deficit/hyperactivity disorder. Biol Psychiatry. 2005;57(5):456-463.

39. Weisler RH, Biederman J, Spencer TJ, et al. Mixed amphetamine salts extended-release in the treatment of adult ADHD: a randomized, controlled trial. CNS Spectr. 2006;11(8):625-639.

40. Spencer T, Wilens T, Biederman, Faraone S, Ablon S, Lapey K. A double - blind, crossover comparison of methylphenidate and placebo in adults with childhood onset attention - deficit hyperactivity disorder. Arch Gen Psychiatry. 1995;52:434-443.

41. Adler LA, Goodman DW, Kollins SH, et al. Double-blind, placebocontrolled study of the efficacy and safety of lisdexamfetamine dimesylate in adults with attention-deficit/hyperactivity disorder. J Clin Psychiatry. 2008;69(9):1364-1373.

42. Michelson D, Adler L, Spencer T, et al. Atomoxetine in adults with ADHD: two randomized, placebo-controlled studies. Biol Psychiatry. 2003;53(2):112-120.
43. Adler LA, Spencer TJ, Williams DW, Moore RJ, Michelson D Long-term, open-label safety and efficacy of atomoxetine in adults with ADHD:final report of a 4-year study. J Atten Disord. 2008;12(3): 248-253.

44. Van Brunt DL, Johnston JA, Ye W, et al. Factors associated with initiation with atomoxetine versus stimulants in the treatment of adults with ADHD: retrospective analysis of administrative claims data. J Manag Care Pharm. 2006;12(3):230-238.

45. Wilens TE, Spencer TJ, Biederman J. A review of the pharmacotherapy of adults with attention-deficit/hyperactivity disorder. J Atten Disord. 2002;5(4):189-202.

46. Higgins ES. J A comparative analysis of antidepressants and stimulants for the treatment of adults with attention-deficit hyperactivity disorder. J Fam Pract. 1999;48(1):15-20.

47. Verbeeck W, Tuinier S, Bekkering GE. Antidepressants in the treatment of adult attention-deficit hyperactivity disorder: a systematic review. Adv Ther. 2009;26(2):170-184.

48. Connor DF, Fletcher KE, Swanson JM. A meta-analysis of clonidine for symptoms of attention-deficit hyperactivity disorder. $\mathrm{J} \mathrm{Am} \mathrm{Acad}$ Child Adolesc Psychiatry. 1999;38(12):1551-1559.

49. Lindsay SE, Gudelsky GA, Heaton PC. Use of modafinil for the treatment of attention deficit/hyperactivity disorder. Ann Pharmacother. 2006;40(10):1829-1833.

50. Elia J, Borcherding BG, Potter WZ, Mefford IN, Rapoport JL, Keysor CS. Stimulant drug treatment of hyperactivity: biochemical correlates. Clin Pharmacol Ther. 1990;48(1):57-66.

51. Krause J. SPECT and PET of the dopamine transporter in attentiondeficit/hyperactivity disorder. Expert Rev Neurother. 2008;8(4): 611-625.

52. Krause KH, Dresel SH, Krause J, Kung HF, Tatsch K. Increased striatal dopamine transporter in adult patients with attention deficit hyperactivity disorder: effects of methylphenidate as measured by single photon emission computed tomography. Neurosci Lett. 2000;285(2): 107-110.

53. Faraone SV, Spencer T, Aleardi M, Pagano C, Biederman J. Meta-analysis of the efficacy of methylphenidate for treating adult attention-deficit/ hyperactivity disorder. J Clin Psychopharmacol. 2004;24(1):24-29.

54. Lutton ME, Leach L, Triezenberg D. Clinical inquiries. Does stimulant therapy help adult ADHD? J Fam Pract. 2003;52(11):888-889, 892.

55. Medori R, Ramos-Quiroga JA, Casas M, Kooij JJ, et al. A randomized, placebo-controlled trial of three fixed dosages of prolonged-release OROS methylphenidate in adults with attention-deficit/hyperactivity disorder. Biol Psychiatry. 2008;63(10):981-989.

56. Jain U, Hechtman L, Weiss M, et al. Efficacy of a novel biphasic controlled-release methylphenidate formula in adults with attentiondeficit/hyperactivity disorder: results of a double-blind placebocontrolled crossover study. J Clin Psychiatry. 2007;68(2):268-277.

57. Reimherr FW, Williams ED, Strong RE, Mestas R, Soni P, Marchant BK. A double-blind, placebo-controlled, crossover study of osmotic release oral system methylphenidate in adults with ADHD with assessment of oppositional and emotional dimensions of the disorder. J Clin Psychiatry. 2007;68(1):93-101.

58. Biederman J, Mick E, Surman C, et al. A randomized, placebocontrolled trial of OROS methylphenidate in adults with attentiondeficit/hyperactivity disorder. Biol Psychiatry. 2006;59(9):829-835.

59. Biederman J, Mick EO, Surman C, et al. Comparative acute efficacy and tolerability of OROS and immediate release formulations of methylphenidate in the treatment of adults with attention-deficit/hyperactivity disorder. BMC Psychiatry. 2007;4(7):49.

60. Fallu A, Richard C, Prinzo R, Binder C. Does OROS-methylphenidate improve core symptoms and deficits in executive function? Results of an open-label trial in adults with attention deficit hyperactivity disorder. Curr Med Res Opin. 2006;22(12):2557-2566.

61. Rösler M, Fischer R, Ammer R, Ose C, Retz W. A randomised, placebocontrolled, 24-week, study of low-dose extended-release methylphenidate in adults with attention-deficit/hyperactivity disorder. Eur Arch Psychiatry Clin Neurosci. 2009;259(2):120-129. 
62. Reinhardt MC, Benetti L, Victor MM, Grevet EH, et al. Is age-at-onset criterion relevant for the response to methylphenidate in attention-deficit/ hyperactivity disorder? J Clin Psychiatry. 2007;68(7):1109-1116.

63. Gorman EB, Klorman R, Thatcher JE, Borgstedt AD. Effects of methylphenidate on subtypes of attention-deficit/hyperactivity disorder. J Am Acad Child Adolesc Psychiatry. 2006;45(7):808-816.

64. Biederman J, Monuteaux MC, Spencer T, Wilens TE, Macpherson HA, Faraone SV. Stimulant therapy and risk for subsequent substance use disorders in male adults with ADHD: a naturalistic controlled 10-year follow-up study. Am J Psychiatry. 2008;165(5):597-603.

65. Levin FR, Evans SM, Brooks DJ, Garawi F. Treatment of cocaine dependent treatment seekers with adult ADHD: double-blind comparison of methylphenidate and placebo. Drug Alcohol Depend. 2007; 87(1):20-29.

66. Peterson K, McDonagh MS, Fu R. Comparative benefits and harms of competing medications for adults with attention-deficit hyperactivity disorder: a systematic review and indirect comparison meta-analysis. Psychopharmacology (Berl). 2008;197(1):1-11.

67. Kuperman S, Perry PJ, Gaffney GR, et al. Bupropion SR vs methylphenidate vs placebo for attention deficit hyperactivity disorder in adults. Ann Clin Psychiatry. 2001;13(3):129-134.

68. Levin FR, Evans SM, Brooks DJ, Kalbag AS, Garawi F, Nunes EV. Treatment of methadone-maintained patients with adult ADHD: doubleblind comparison of methylphenidate, bupropion and placebo. Drug Alcohol Depend. 2006;81(2):137-148.

69. Palumbo DR, Sallee FR, Pelham WE Jr, Bukstein OG, Daviss WB, McDermott MP. Clonidine for attention-deficit/hyperactivity disorder: I. Efficacy and tolerability outcomes. J Am Acad Child Adolesc Psychiatry. 2008;47(2):180-218.

70. Low K, Gendaszek AE. Illicit use of psychostimulants among college students: a preliminary study. Psychol Health Med. 2002;7:283-287.

71. Weisler RH, Biederman J, Spencer TJ, Wilens TE. Long-term cardiovascular effects of mixed amphetamine salts extended release in adults with ADHD. CNS Spectr. 2005;10(12 Suppl 20):35-43.
72. Wilens TE, Hammerness PG, Biederman J, et al. Blood pressure changes associated with medication treatment of adults with attentiondeficit/hyperactivity disorder. J Clin Psychiatry. 2005;66(2): 253-259.

73. Vetter VL, Elia J, Erickson C, et al. Cardiovascular monitoring of children and adolescents with heart disease receiving stimulant drugs: a scientific statement from the American Heart Association Council on Cardiovascular Disease in the Young Congenital Cardiac Defects Committee and the Council on Cardiovascular Nursing. Circulation. 2008;117(18):2407-2423.

74. Center for Drug Evaluation and Research. Food and Drug Administration Web site. Available from: www.accessdata.fda.gov/scripts/cder/ drugsatfda. Accessed June 16, 2009.

75. Briggs, GG, Freman RK, Yaffe SJ. Drugs in Pregnancy and Lactation, 7th edition. Lippincott Williams \& Wilkins; 2005. p. 1056-1057.

76. Golub M, Costa L, Crofton K, et al. NTP-CERHR Expert Panel Report on the reproductive and developmental toxicity of methylphenidate. Birth Defects Res B Dev Reprod Toxicol. 2005;74(4): 300-381.

77. Einarson A. Abrupt discontinuation of psychotropic drugs following confirmation of pregnancy: a risky practice. J Obstet Gynaecol Can. 2005;27(11):1019-1022.

78. King S, Griffin S, Hodges Z, et al. A systematic review and economic model of the effectiveness and cost-effectiveness of methylphenidate, dexamfetamine and atomoxetine for the treatment of attention deficit hyperactivity disorder in children and adolescents. Health Technol Assess. 2006;10(23):iii-iv, xiii-146.

79. Marchetti A, Magar R, Lau H, et al. Pharmacotherapies for attentiondeficit/hyperactivity disorder: expected-cost analysis. Clin Ther. 2001; 23(11):1904-1921.

80. Wu EQ, Birnbaum HG, Zhang HF, Ivanova JI, Yang E, Mallet D. Health care costs of adults treated for attention-deficit/hyperactivity disorder who received alternative drug therapies. J Manag Care Pharm. 2007;13(7):561-569.
Neuropsychiatric Disease and Treatment

\section{Publish your work in this journal}

Neuropsychiatric Disease and Treatment is an international, peerreviewed journal of clinical therapeutics and pharmacology focusing on concise rapid reporting of clinical or pre-clinical studies on a range of neuropsychiatric and neurological disorders. This journal is indexed on PubMed Central, the 'PsycINFO' database and CAS, and is the official

\section{Dovepress}

journal of The International Neuropsychiatric Association (INA). The manuscript management system is completely online and includes a very quick and fair peer-review system, which is all easy to use. Visit $\mathrm{http}: / / \mathrm{www}$. dovepress.com/testimonials.php to read real quotes from published authors. 